\title{
Effect of High Body Mass Index on Short- and Long- term Outcomes of Patients who Underwent Laparoscopic Gastrectomy for Advanced Gastric Cancer: A Case Control Study
}

\section{Tianqi Luo}

Sun Yat-sen University Cancer Center

Guoming Chen

Sun Yat-sen University Cancer Center

Chengcai Liang

Sun Yat-sen University Cancer Center

Kaiming Jiang

Sun Yat-sen University Cancer Center

Kai Lei

Sun Yat-sen University First Affiliated Hospital

Shuqiang Yuan

Sun Yat-sen University Cancer Center

Haibo Qiu

Sun Yat-sen University Cancer Center

Yao Liang

Sun Yat-sen University Cancer Center

Ying-Bo Chen ( $\nabla$ chenyb@sysucc.org.cn )

Sun Yat-sen University Cancer Center https://orcid.org/0000-0003-2509-3381

Research

Keywords: Gastric cancer, laparoscopic gastrectomy, body mass index

Posted Date: February 6th, 2020

DOI: https://doi.org/10.21203/rs.2.22786/v1

License: (c) (1) This work is licensed under a Creative Commons Attribution 4.0 International License.

Read Full License 


\section{Abstract}

\section{Background}

High body mass index (BMI) is thought to be a preoperative risk factor for surgical treatment. Until now, few studies have investigated the long-term impact of preoperative high BMI on advanced gastric cancer (GC) patients who underwent laparoscopic gastrectomy (LG). Therefore, the present study was designed to compare clinical outcomes between high BMI and normal BMI patients who underwent LG.

\section{Methods}

We retrospectively investigated 282 pathological stage II III GC cases who underwent radical LG plus D2 lymphadenectomy from February 2009 to May 2018. Based on the China BMI classification, the patients were classified into a high (BMI $\geq 24 \mathrm{~kg} / \mathrm{m} 2)$ or normal (BMI $<24 \mathrm{~kg} / \mathrm{m} 2)$ BMl group. The clinical characteristics, intraoperative findings, short-term and long-term outcomes of the two groups of patients were then compared.

Results

The high BMI group had longer operation time (160.1 \pm 36.0 minutes vs. $147.7 \pm 33.7$ minutes; $\mathrm{P}=0.005)$ and greater intraoperative bleeding $(138.3 \pm 239.4 \mathrm{ml} v$ s. $86.6 \pm 67.7 \mathrm{ml} ; \mathrm{P}=0.002)$ compared to the normal BMI group. Moreover, shorter time to flatus, starting the soft diet, removing drain tube and length of stay (all $P<0.05$ ) were observed in the high BMI patients. However, there was no significant difference in relapse-free survival or overall survival between the two groups.

\section{Conclusion}

Patients with high BMI was associated with longer operation time and greater amount of intraoperative bleeding but had faster recovery as compared to those with normal BMI. Also, LG can be considered as safe with no significant difference in terms of short- and long-term outcomes on the peri- and postoperative outcomes between the two BMI groups of patients. Nevertheless, these surgeries for high BMI patients should be performed by experienced surgeons.

\section{Background}

In China, gastric cancer (GC) is the second most frequently diagnosed type of cancer and the third primary cause of cancer death $[2,6]$. Radical gastrectomy with $D 2$ lymphadenectomy remains the only standard treatment for resectable GC [15]. Since laparoscopic gastrectomy (LG) was first reported by Kitano et al in 1994 for the treatment of early-stage GC, this technique has been rapidly adopted in the surgical treatment of GC [13]. Several prospective randomized trials have confirmed the feasibility and safety of $L G$ compared with traditional open surgery. The benefits of $L G$ include minimal invasiveness, the amplification of the surgical field of vision, shorter duration of operation, fewer perioperative complications and faster recovery after surgery compared to open surgery $[10,12,14]$. Although 
laparoscopy surgery is popular in the treatment of GC, its utility for treating obese GC patients remains controversial. High body mass index (BMI) is generally thought to be a preoperative risk factor for surgical treatment. Theoretically, high BMI patients have more comorbidities, such as hypertension, diabetes, heart disease, which may consequently increase surgical difficulty and the incidence of postoperative complications $[3,20]$. Accordingly, in GC surgery, high BMI was found to have an adverse impact on lymph node dissection and prognosis of the patients [4, 5]. Since 2003, several investigators began to explore whether laparoscopic-assisted distal gastrectomy (LADG) could be beneficial for overweight patients with early GC [17]. However, these previous researches mainly focused on the shortterm outcome of laparoscopic-assisted gastrectomy for early GC between the high BMI and normal BMI patients $[11,18,28]$. Until now, few studies have investigated the long-term outcomes of performing $L G$ to advanced GC patients with high preoperative BMI. Therefore, we conducted the present work to explore the impact of high BMI on the short- and long-term outcomes of advanced GC patients who underwent LG.

\section{Materials And Methods}

\section{Patients and variables}

We retrospectively investigated the data of $462 \mathrm{GC}$ cases who had underwent radical LG plus D2 lymphadenectomy at Sun Yat-sen University Cancer Center between February 2009 and May 2018, after obtaining our institutional review board approval. Characteristics and clinicopathologic variables including age, sex, height, weight, BMI, tumor size, histology grade, ASA (American society of anesthesiologists), LG extent and AJCC (American Joint Committee on Cancer) stage were analyzed. Surgery-related variables including operation time, intraoperative blood loss, number of retrieved lymph nodes, number of positive lymph nodes, resection margin, digestive tract reconstruction and type of gastrectomy were retrieved. Treatment-related variables including the information of neoadjuvant and adjuvant chemotherapy were also analyzed. Postoperative variables include time to flatus, time of starting soft diet, removal of drainage tube, length of stay, transfusion rate and postoperative complication.

Based on the China BMI classification, the patients were classified into a high BMI (BMI $\geq 24 \mathrm{~kg} / \mathrm{m}^{2}$ ) or normal BMI $\left(\mathrm{BMl}<24 \mathrm{~kg} / \mathrm{m}^{2}\right)$ group. The BMl was calculated as the weight $(\mathrm{kg})$ of the patients divided by their corresponding height squared $\left(\mathrm{m}^{2}\right)$. All postoperative TNM staging of patients were defined by the AJCC 7th edition. The definition of postoperative complications was based on the Clavien-Dindo classification [9]. Patients who had distant metastasis $(n=44)$ and stage I disease $(n=136)$ were excluded. Finally, a total of 282 patients who underwent radical LG plus D2 lymphadenectomy for II III stage GC was used for analysis.

\section{laparoscopic procedure}

All patients were placed in a herringbone position under general anesthesia. The surgeon was always located on the left side of the patient. The assistant was on the right side of the patient and the monitor 
was between patient's legs. Our laparoscopic incision was performed with five trocars, including two 12$\mathrm{mm}$ trocars and three 5-mm trocars. Primarily, a 12-mm camera trocar was positioned above the level of the umbilicus. Then, the surgeon pierced a 12-mm trocar in the left upper abdomen and a 5-mm trocar in the left lateral abdomen. The two 5-mm trocars were positioned at the right upper and right lateral abdomen respectively by the assistant. Pneumoperitoneum was set at the level of $10-12 \mathrm{mmHg}$ during surgery. Then, a harmonic scalpel was used for dividing the tissues and dissecting lymph nodes. Distal or total gastrectomy was performed based on tumor size, location, and depth of invasion. D2 lymphadenectomy was performed according to the Japanese GC Treatment Guidelines and CSCO (The Chinese Society of Clinical Oncology) Clinical Guidelines for GC [7, 24]. Furthermore, laparoscopic spleenpreserving splenic hilar lymphadenectomy (LSPL) was performed if the tumor had invaded the splenic fossa or the lymph nodes of the splenic fossa were found to be swollen. Both the stomach and duodenum were dissected using stapler. After the above steps were completed, the gastrointestinal tract was reconstructed using the Billroth II or Roux-en-Y gastrojejunostomy according to the type of gastrectomy. Next, a nasogastric tube was routinely placed across the anastomotic stoma following anastomosis. Finally, the abdominal drain tube was typically placed under the caudate lobe of the liver.

\section{Statistical analyses}

Data were analyzed using the R software version 3.6.0 (http://www.r-project.org). Continuous variables were analyzed using the Student's t-test or Mann-Whitney U-test and were presented as their mean \pm SD. The Chi-square test and Fisher's exact test were performed to analyze categorical variables. Overall survival was defined as the length of time from the date of $L G$ to death from any cause. Relapse-free survival was defined as the length of time from the date of primary surgery for GC to the appearance of signs or symptoms of that cancer. Survival curves were estimated using the Kaplan-Meier method, and statistical differences were examined using the log-rank test. Univariate and multivariate survival analyses were performed using the likelihood ratio test of the stratified Cox proportional hazards model. All $P$ values were based on two-sided statistical tests and $p<0.05$ was considered statistically significant.

\section{Result}

\section{Baseline characteristics}

The baseline characteristics of the 282 investigated advanced GC patients are displayed in Table 1. There were 210 patients in the normal BMI group and 72 patients in the high BMI group. The mean BMI was $20.6 \mathrm{~kg} / \mathrm{m}^{2}$ in the normal BMI group and $26.5 \mathrm{~kg} / \mathrm{m}^{2}$ in the high BMI group $(P<0.001)$ respectively. However, there were no differences between the two groups in terms of sex, age, ASA, tumor size, histology grade, pathological TNM stage and LG extent (all $P>0.05$ ). Moreover, a total of 11 patients received neoadjuvant chemotherapy before surgery (high $\mathrm{BMI}$ vs. normal BMl; $1.4 \%$ vs. $4.8 \%$; $\mathrm{P}=0.356$ ).

\section{Short-term outcome}


The intraoperative and postoperative outcomes of the 282 patients are shown in Table 2. There were no differences in terms of the number of retrieved lymph nodes, transfusion rate and positive surgical margin between the two groups $(P>0.05)$. However, compared to normal BMI patients, the high BMI group was associated with longer operation time $(160.1 \pm 36.0$ minutes vs. $147.7 \pm 33.7$ minutes; $P=$ $0.005)$ and greater amount of intraoperative bleeding $(138.3 \pm 239.4 \mathrm{~mL}$ vs. $86.6 \pm 67.7 \mathrm{~mL} ; \mathrm{P}=0.002)$. However, the time to flatus ( $3.7 \pm 1.1$ vs. $4.3 \pm 2.1$ days; $P=0.006)$, start of soft diet $(4.9 \pm 1.3$ vs. $5.7 \pm 2.6$ days; $P=0.002)$, removal of drainage tube $(5.1 \pm 1.1$ vs. $5.8 \pm 3.2$ days; $P=0.002)$ and hospitalization $(7.3$ \pm 2.3 vs. $8.9 \pm 5.2$ days; $P=0.002$ ) was significantly shorter for the high $B M I$ group.

The local and systemic complications after surgery are listed in Table 3. A total of 25 patients (high BMI group: 7; normal BMI group: 18) in the overall cohort experienced postoperative complications. The main postoperative complication in the normal BMI group was abdominal bleeding $(n=4 ; 1.9 \%)$. Pneumonia was the leading postoperative complication in the high BMI group $(n=3 ; 4.1 \%)$. Besides, no postoperative wound infection occurred in the two groups. The local (high BMI vs. normal BMI group; $5.6 \%$ vs. $7.1 \% ; P=$ $0.848)$, systemic ( $4.1 \%$ vs. $1.5 \% ; P=0.360)$ and overall complications $(9.7 \%$ vs. $8.6 \% ; P=0.955)$ were not significantly different between the two BMI groups, and no perioperative mortality was observed in both groups.

\section{Long-term outcome}

The overall survival and relapse-free survival of the patients are summarized in Fig. 1a and Fig. 1b, respectively. A total of 142 patients in the normal BMI group (67.6\%) and 54 patients $(75.0 \%)$ in high BMI group underwent adjuvant chemotherapy after laparoscopic gastrectomy $(P=0.305)$. In our study, the median follow-up time was 18 months in the high BMI group and 20 months in the normal BMI group ( $P$ $=0.468$ ). During the follow-up period, 23 patients in the high BMI group and 62 patients in normal the BMI group showed signs of recurrence after surgery $(P=0.812)$. The most common sites of recurrence were the anastomotic stoma $(n=8 ; 11.1 \%)$ and peritoneum $(n=7 ; 9.7 \%)$ for the high BMI group, while for the normal BMI group it was distant nodal metastases $(n=19 ; 9.0 \%)$ and anastomotic recurrence $(n=18$; 8.6\%) (Table 4). We also found that during follow-up, there were 7 (9.7\%) and 24 patients $(11.4 \%)$ from the high BMI group and normal BMI group, respectively, who succumbed to their disease. However, the relapse-free survival $(P=0.449)$ and overall survival $(P=0.903)$ time were comparable between the patients from both groups. Univariate analyses demonstrated that tumor invasion depth (T3/T4; HR = 5.139, 95\% Cl: $1.264-20.900 ; \mathrm{P}=0.022)$ and tumor size ( $\geq 5 \mathrm{~cm} ; \mathrm{HR}=1.794,95 \% \mathrm{Cl}: 1.109-2.904 ; \mathrm{P}=$ 0.017 ) were adversely associated with the prognosis of patients (Table 5). However, on multivariate analyses, only tumor invasion depth (T3/T4; $\mathrm{HR}=4.210,95 \% \mathrm{Cl}: 1.020-17.382 ; \mathrm{P}=0.047)$ was identified as the independent risk factor for recurrence (Table 6).

\section{Discussion}

High BMI has been considered as a risk factor for surgery because of the technical difficulties it poses to the surgeons. However, with the development of laparoscopic technology, the negative effects of high BMI have been theoretically weakened [27]. Son et al. revealed that LG was associated with lesser 
intraoperative blood loss and faster recovery of bowel movement as compared to open gastrectomy in patients with a $\mathrm{BMI} \geq 30 \mathrm{~kg} / \mathrm{m}^{2}$ [22]. Accordingly, many researches began to explore the impact of preoperative high BMI on laparoscopic gastrectomy. Nevertheless, few studies have investigated the clinical impact of preoperative high BMI on advanced GC patients who underwent laparoscopic gastrectomy. Therefore, the present study was designed to compare clinical outcomes between high BMI and normal BMI patients who underwent LG.

During surgery, excessive visceral fat tends to impair the exposure of blood vessels, which may increase the risk of accidental injury to the neighboring blood vessels. Similarly, extra time will be consumed in dissecting the intra-abdominal adipose tissue, which leads to a longer duration of surgery. In accordance with previous studies $[1,21,23]$, our study found that patients with high BMI had longer operation time and more intraoperative bleeding as compared to patients with normal BMI during the laparoscopic procedures. Moreover, our findings showed that high BMI was associated with shorter time to flatus, start of soft diet, drain tube removal and hospitalization (all $\mathrm{P}<0.05$ ), which was rarely reported before. We considered that this faster recovery should attribute to the better ability of nutrients absorption in high BMI patients. In terms of postoperative complications, the incidence rate was similar between the two BMI groups, which was consistent with previous studies $[16,19,26]$. In addition, there was no incidence of postoperative wound infections in both groups which we believe was attributed to the improvement of asepsis cognition and in laparoscopy in reducing the size of the abdominal incisions.

The dilemma of whether high BMI has an impact on lymph node dissection of LG remains debatable. While Shimada et al. reported that patients with high BMI were at a higher risk for insufficient regional lymph nodes removal, leading to an increased risk of local recurrence and worse survival [16, 21], several studies have reported that excessive fat had little effect on the number of retrieved lymph nodes during LG $[1,11,17,18,23,26,28]$. Our study indicated that no significant difference was observed in terms of the number of retrieved lymph nodes between the two BMI groups.

Further, due to the deep location of the splenic fossa, visceral adipose tissue of high BMI patients tends to cover the spleen, leading to the hampering and obscuring of surgical visibility during laparoscopic spleen-preserving splenic hilar lymphadenectomy (LSPL). Thereby, we also assessed the safety and feasibility of LSPL in both groups. Our result indicated that the incidence of lymphadenectomy for station number $10(19.4 \%$ vs. $19.0 \% ; P=1.000)$ and the number of retrieved lymph nodes at station number 10 $(1.8 \pm 1.5$ vs. $2.8 \pm 2.8 ; P=0.194)$ were similar in the two groups, which indicate that LSPL can be performed safely for high BMI patients with GC; at least in our cancer center which is a high cancer volume institution. However, we should note that these surgeries in our study were mainly performed by surgeons with advanced experience in laparoscopic gastrectomy. Lee et al. reported that surgeons without adequate accumulation of laparoscopic experience may lead to an inadequate lymph node dissection for high BMI patients [16]. Also, it has been reported that performing less than 45 cases of LG was associated with a higher incidence of complications [8]. Therefore, we recommend that laparoscopic surgery for high BMI patients should be performed by experienced surgeons to ensure feasibility and safety. 
The long-term outcomes of high BMI in LG remain controversial. Wang et al. reported that high BMI does not adversely affect long-term outcomes of patients who underwent LADG [26]. However, the finding of Shimada et al. showed that the 5-year disease-specific survival was significantly lower in high BMI patients who underwent LADG than normal BMI patients; which may be partly attributed to the decreased number of the retrieved lymph node that could induce the adverse prognosis in the high BMI patients [21]. In the present study, we found that with adequate dissected number of lymph nodes, the survival outcomes were comparable between high and normal BMI (3-year overall survival: $92.4 \%$ vs. $77.6 \%, \mathrm{P}=$ 0.507 ; 3 -year relapse-free survival: $49.7 \%$ vs. $58.2 \%, P=0.402$ ). However, the univariate and multivariate analysis did not show that BMI can be considered as an independent risk factor for recurrence.

Despite the promising findings presented, the present study constrained with several limitations. First, this was a retrospective study from a single institution, thus further validation of the study results are to be performed. Second, we assessed the fat content of the abdominal cavity based on only the BMI criteria of the Chinese BMI classification and we have to emphasize that the distribution of fat may be different between individuals. Therefore, more comprehensive indexes should be used to evaluate the fat content of the abdominal cavity, such as BSA (body surface area), VFA (visceral fat area) and SFA (subcutaneous fat area), in the future. [22]. Lastly, our study did not include information on the comorbidity of the patients, such as hypertension, diabetes and heart disease, which could have also been considered as a risk factor for postoperative complications of LG [25].

\section{Conclusion}

In conclusion, our study indicated that high BMI correlated with longer operation time and more intraoperative bleeding. However, high BMI patients were associated with faster recovery. With sufficient dissected lymph nodes, the long-term survival outcomes of patients with high BMI were comparable to that of patients with normal BMI. Therefore, LG can be performed safely in high BMI patients of advanced GC. However, LG for high BMI patients should be performed by experienced surgeons.

\section{List Of Abbreviations}

High body mass index (BMI); gastric cancer (GC); laparoscopic gastrectomy (LG); laparoscopic-assisted distal gastrectomy (LADG); laparoscopic spleen-preserving splenic hilar lymphadenectomy (LSPL); BSA (body surface area), VFA (visceral fat area) and SFA (subcutaneous fat area)

\section{Declarations}

\section{Ethics approval and consent to participate}

Not applicable

\section{Consent for publication}


Not applicable

\section{Competing interests}

The authors declare that they have no competing interests.

\section{Funding}

This research was not solicited and did not receive any specific grant from funding agencies in the public, commercial, or not-for-profit sectors.

\section{Authors' contributions}

LTQ, CGM, and LCC collected data and wrote the manuscript. JKM and LK analyzed and interpreted the data. YSQ, QHB, LY, and CYB provided professional support and revised the manuscript. All authors read and approved the final manuscript.

\section{Availability of data and materials}

The datasets used during the current study are available from the corresponding author on reasonable request.

\section{Acknowledgements}

Not applicable

\section{References}

[1] Chen K, Pan Y, Zhai ST, Cai JQ, Chen QL, Chen DW, Zhu YP, Zhang Y, Zhang YP, Maher H, Wang XF (2017): Laparoscopic gastrectomy in obese gastric cancer patients: a comparative study with non-obese patients and evaluation of difference in laparoscopic methods. BMC Gastroenterol 17, 78.

[2] Chen W, Sun K, Zheng R, Zeng H, Zhang S, Xia C, Yang Z, Li H, Zou X, He J (2018): Cancer incidence and mortality in China, 2014. Chin J Cancer Res 30, 1-12.

[3] Choban PS, Flancbaum L (1997): The impact of obesity on surgical outcomes: a review. Journal of the American College of Surgeons 185, 593-603.

[4] Dhar DK, Kubota H, Tachibana M, Kotoh T, Tabara H, Masunaga R, Kohno H, Nagasue N (2000): Body mass index determines the success of lymph node dissection and predicts the outcome of gastric carcinoma patients. Oncology 59, 18-23.

[5] Feng F, Zheng G, Guo X, Liu Z, Xu G, Wang F, Wang Q, Guo M, Lian X, Zhang H (2018): Impact of body mass index on surgical outcomes of gastric cancer. BMC Cancer 18, 151. 
[6] Gao K, Wu J (2019): National trend of gastric cancer mortality in China (2003-2015): a populationbased study. Cancer Commun (Lond) 39, 24.

[7] Japanese Gastric Cancer A (2017): Japanese gastric cancer treatment guidelines 2014 (ver. 4). Gastric Cancer 20, 1-19.

[8] Jeong O, Ryu SY, Choi WY, Piao Z, Park YK (2014): Risk factors and learning curve associated with postoperative morbidity of laparoscopic total gastrectomy for gastric carcinoma. Ann Surg Oncol 21, 2994-3001.

[9] Katayama H, Kurokawa Y, Nakamura K, Ito H, Kanemitsu Y, Masuda N, Tsubosa Y, Satoh T, Yokomizo A, Fukuda H, Sasako M (2016): Extended Clavien-Dindo classification of surgical complications: Japan Clinical Oncology Group postoperative complications criteria. Surg Today 46, 668-685.

[10] Kim HH, Hyung WJ, Cho GS, Kim MC, Han SU, Kim W, Ryu SW, Lee HJ, Song KY (2010): Morbidity and mortality of laparoscopic gastrectomy versus open gastrectomy for gastric cancer: an interim report-a phase III multicenter, prospective, randomized Trial (KLASS Trial). Ann Surg 251, 417-420.

[11] Kim KH, Kim MC, Jung GJ, Kim HH (2006): The impact of obesity on LADG for early gastric cancer. Gastric Cancer 9, 303-307.

[12] Kim MC, Kim W, Kim HH, Ryu SW, Ryu SY, Song KY, Lee HJ, Cho GS, Han SU, Hyung WJ, Korean Laparoscopic Gastrointestinal Surgery Study G (2008): Risk factors associated with complication following laparoscopy-assisted gastrectomy for gastric cancer: a large-scale korean multicenter study. Ann Surg Oncol 15, 2692-2700.

[13] Kitano S, Iso Y, Moriyama M, Sugimachi K (1994): Laparoscopy-assisted Billroth I gastrectomy. Surgical laparoscopy \& endoscopy 4, 146-148.

[14] Kitano S, Shiraishi N, Uyama I, Sugihara K, Tanigawa N, Japanese Laparoscopic Surgery Study G (2007): A multicenter study on oncologic outcome of laparoscopic gastrectomy for early cancer in Japan. Ann Surg 245, 68-72.

[15] Kiyokawa T, Fukagawa T (2019): Recent trends from the results of clinical trials on gastric cancer surgery. Cancer Commun (Lond) 39, 11.

[16] Lee HJ, Kim HH, Kim MC, Ryu SY, Kim W, Song KY, Cho GS, Han SU, Hyung WJ, Ryu SW, Korean Laparoscopic Gastrointestinal Surgery Study G (2009): The impact of a high body mass index on laparoscopy assisted gastrectomy for gastric cancer. Surg Endosc 23, 2473-2479.

[17] Noshiro H, Shimizu S, Nagai E, Ohuchida K, Tanaka M (2003): Laparoscopy-assisted distal gastrectomy for early gastric cancer: is it beneficial for patients of heavier weight? Ann Surg 238,680 685 . 
[18] Ojima T, Iwahashi M, Nakamori M, Nakamura M, Takifuji K, Katsuda M, lida T, Tsuji T, Hayata K, Yamaue H (2012): The impact of abdominal shape index of patients on laparoscopy-assisted distal gastrectomy for early gastric cancer. Langenbecks Arch Surg 397, 437-445.

[19] Oki E, Sakaguchi Y, Ohgaki K, Saeki H, Chinen Y, Minami K, Sakamoto Y, Toh Y, Kusumoto T, Okamura T, Maehara Y (2012): The impact of obesity on the use of a totally laparoscopic distal gastrectomy in patients with gastric cancer. J Gastric Cancer 12, 108-112.

[20] Pi-Sunyer FX (1993): Medical hazards of obesity. Annals of internal medicine 119, 655-660.

[21] Shimada S, Sawada N, Ishiyama Y, Nakahara K, Maeda C, Mukai S, Hidaka E, Ishida F, Kudo SE (2018): Impact of obesity on short- and long-term outcomes of laparoscopy assisted distal gastrectomy for gastric cancer. Surg Endosc 32, 358-366.

[22] Son SY, Jung DH, Lee CM, Ahn SH, Ahn HS, Park DJ, Kim HH (2015): Laparoscopic gastrectomy versus open gastrectomy for gastric cancer in patients with body mass index of $30 \mathrm{~kg} / \mathrm{m} 2$ or more. Surg Endosc 29, 2126-2132.

[23] Sugimoto M, Kinoshita T, Shibasaki H, Kato Y, Gotohda N, Takahashi S, Konishi M (2013): Short-term outcome of total laparoscopic distal gastrectomy for overweight and obese patients with gastric cancer. Surg Endosc 27, 4291-4296.

[24] Wang FH, Shen L, Li J, Zhou ZW, Liang H, Zhang XT, Tang L, Xin Y, Jin J, Zhang YJ, Yuan XL, Liu TS, Li GX, Wu Q, Xu HM, Ji JF, Li YF, Wang X, Yu S, Liu H, Guan WL, Xu RH (2019): The Chinese Society of Clinical Oncology (CSCO): clinical guidelines for the diagnosis and treatment of gastric cancer. Cancer Commun (Lond) 39, 10.

[25] Wang JB, Zheng CH, Li P, Xie JW, Lin JX, Lu J, Chen QY, Cao LL, Lin M, Huang CM (2017): Effect of comorbidities on postoperative complications in patients with gastric cancer after laparoscopy-assisted total gastrectomy: results from an 8-year experience at a large-scale single center. Surg Endosc 31, 26512660.

[26] Wang Z, Zhang X, Liang J, Hu J, Zeng W, Zhou Z (2015): Short-term outcomes for laparoscopyassisted distal gastrectomy for body mass index $>/=30$ patients with gastric cancer. J Surg Res $195,83-$ 88.

[27] Yamada H, Kojima K, Inokuchi M, Kawano T, Sugihara K (2008): Effect of obesity on technical feasibility and postoperative outcomes of laparoscopy-assisted distal gastrectomy-comparison with open distal gastrectomy. J Gastrointest Surg 12, 997-1004.

[28] Yasuda K, Inomata M, Shiraishi N, Izumi K, Ishikawa K, Kitano S (2004): Laparoscopy-assisted distal gastrectomy for early gastric cancer in obese and nonobese patients. Surg Endosc 18, 1253-1256. 


\section{Tables}

Page $11 / 18$ 


\begin{tabular}{|c|c|c|c|}
\hline \multicolumn{4}{|c|}{ Table1. Patient Characteristics } \\
\hline Variable & Normal BMI & High BMI & $P$-value \\
\hline $\mathrm{N}$ & 210 & 72 & \\
\hline Sex & & & 1 \\
\hline Male & $144(68.6 \%)$ & $50(69.4 \%)$ & \\
\hline Female & $66(31.4 \%)$ & $22(30.6 \%)$ & \\
\hline Age (year) & $57.8 \pm 11.7$ & $58.1 \pm 11.7$ & 0.969 \\
\hline Height $(\mathrm{cm})$ & $164.3 \pm 7.3$ & $165.5 \pm 6.3$ & 0.177 \\
\hline Weight (kg) & $55.6 \pm 7.4$ & $72.7 \pm 8.7$ & $<0.001$ \\
\hline $\mathrm{BMI}\left(\mathrm{kg} / \mathrm{m}^{2} \rrbracket\right.$ & $20.6 \pm 2.1$ & $26.5 \pm 2.3$ & $<0.001$ \\
\hline Tumor Size $(\mathrm{cm})$ & $5.6 \pm 2.3$ & $5.4 \pm 2.3$ & 0.758 \\
\hline Histological Grade & & & 0.966 \\
\hline G2 & $21(10.0 \%)$ & $8(21.1 \%)$ & \\
\hline G3 & $189(90.0 \%)$ & $64(88.9 \%)$ & \\
\hline Tumor Depth & & & 0.221 \\
\hline T1 & $4(1.9 \%)$ & $4(5.6 \%)$ & \\
\hline T2 & $14(6.7 \%)$ & $5(6.9 \%)$ & \\
\hline T3 & $123(58.5 \%)$ & $48(66.7 \%)$ & \\
\hline T4a & $65(31.0 \%)$ & $14(19.4 \%)$ & \\
\hline $\mathrm{T} 4 \mathrm{~b}$ & $4(1.9 \%)$ & $1(1.4 \%)$ & \\
\hline Lymph Node Metastasis & & & 0.481 \\
\hline No & $40(19.1 \%)$ & $14(19.4 \%)$ & \\
\hline N1 & $41(19.5 \%)$ & $13(18.1 \%)$ & \\
\hline N2 & 45 (21.4\%) & $20(27.8 \%)$ & \\
\hline N3a & $50(23.8 \%)$ & 19 (26.4\%) & \\
\hline N3b & 34 (16.2\%) & $6(8.3 \%)$ & \\
\hline AJCC Stage & & & 0.733 \\
\hline$\| \mathrm{A}$ & $44(21.0 \%)$ & $17(23.6 \%)$ & \\
\hline IIB & 33 (15.7\%) & 13 (18.1\%) & \\
\hline
\end{tabular}




\begin{tabular}{|lcll|}
\hline IIIA & $48(22.9 \%)$ & $18(25.0 \%)$ & \\
IIIC & $51(24.3 \%)$ & $17(23.6 \%)$ & \\
ASA & $34(16.1 \%)$ & $7(9.7 \%)$ & 0.253 \\
NA & & & \\
I & $1(0.5 \%)$ & $0(0.0 \%)$ & \\
II & $41(19.5 \%)$ & $10(13.9 \%)$ & \\
\hline III & $159(75.7 \%)$ & $55(76.4 \%)$ & \\
\hline LG Extent & $9(4.3 \%)$ & $7(9.7 \%)$ & \\
\hline Assisted & & & \\
\hline Totally & $144(68.6 \%)$ & $50(69.4 \%)$ & \\
\hline Neoadjuvant Chemotherapy & $66(31.4 \%)$ & $22(30.6 \%)$ & \\
\hline No & $200(95.2 \%)$ & $71(98.6 \%)$ & \\
\hline Yes & $10(4.8 \%)$ & $1(1.4 \%)$ & \\
\hline
\end{tabular}

Abbreviations: BMI, body mass index; AJCC, American Joint Committee on Cancer; ASA, American society of anesthesiologists; LG Extent, laparoscopic gastrectomy extent. 


\begin{tabular}{|c|c|c|c|}
\hline Variable & Normal BMI & High BMI & $P$-value \\
\hline Operation Time (minute) & $147.7 \pm 33.7$ & $160.1 \pm 36.0$ & 0.005 \\
\hline Digestive Tract Reconstruction & & & 1 \\
\hline Billroth II & $97(46.2 \%)$ & $33(45.8 \%)$ & \\
\hline Roux-en-Y & $113(53.8 \%)$ & $39(54.2 \%)$ & \\
\hline Type of Gastrectomy & & & 0.143 \\
\hline Total & $88(41.9 \%)$ & $38(52.8 \%)$ & \\
\hline Distal & $122(58.1 \%)$ & $34(47.2 \%)$ & \\
\hline Intraoperative Blood Loss (ml) & $86.6 \pm 67.7$ & $138.3 \pm 239.4$ & 0.002 \\
\hline Transfusion Rate & & & 0.259 \\
\hline No & $190(90.5 \%)$ & $61(84.7 \%)$ & \\
\hline Yes & $20(9.5 \%)$ & $11(15.3 \%)$ & \\
\hline The number of retrieved LNs & $41.8 \pm 16.6$ & $43.3 \pm 17.2$ & 0.447 \\
\hline The number of positive LNs & $7.3 \pm 8.5$ & $6.2 \pm 7.4$ & 0.487 \\
\hline Station10 lymphadenectomy & & & 1 \\
\hline No & $170(81.0 \%)$ & $58(80.6 \%)$ & \\
\hline Yes & $40(19.0 \%)$ & $14(19.4 \%)$ & \\
\hline The number of Station 10 LNs & $2.8 \pm 2.8$ & $1.8 \pm 1.5$ & 0.34 \\
\hline The number of positive LNs at Station 10 & $0.4 \pm 0.8$ & $0.1 \pm 0.3$ & 0.184 \\
\hline Resection Margin & & & 0.547 \\
\hline Ro & 206 (98.1\%) & $72(100.0 \%)$ & \\
\hline R1 & $4(1.9 \%)$ & $0(0.0 \%)$ & \\
\hline Time to Flatus (day) & $4.3 \pm 2.1$ & $3.7 \pm 1.1$ & 0.006 \\
\hline Time to Soft Diet (day) & $5.7 \pm 2.6$ & $4.9 \pm 1.3$ & 0.002 \\
\hline Drainage Time (day) & $5.8 \pm 3.2$ & $5.1 \pm 1.1$ & 0.002 \\
\hline Length of Stay (day) & $8.9 \pm 5.2$ & $7.3 \pm 2.3$ & 0.002 \\
\hline Adjuvant Chemotherapy & & & 0.305 \\
\hline No & 68 (32.4\%) & $18(25.0 \%)$ & \\
\hline
\end{tabular}




\begin{tabular}{|c|c|c|}
\hline Yes & $142(67.6 \%)$ & $54(75.0 \%)$ \\
\hline Mortality & & NA \\
\hline No & 210 (100.0\%) & $72(100.0 \%)$ \\
\hline Yes & $0(0 \%)$ & $0(0 \%)$ \\
\hline
\end{tabular}

Abbreviations: LNs (lymph nodes).

\begin{tabular}{|ccll|}
\hline \multicolumn{3}{|l|}{ Table 3. Postoperative complications } & \\
\hline Variable & Normal BMI/ n (\%) & High BMI/ n (\%) & P-value \\
\hline Overall Complication & $18(8.6 \%)$ & $7(9.7 \%)$ & 0.955 \\
\hline Local Complication & $15(7.1 \%)$ & $4(5.6 \%)$ & 0.848 \\
\hline Abdominal infection & $3(1.4 \%)$ & $1(1.4 \%)$ & \\
\hline Anastomotic leakage & $3(1.4 \%)$ & $0(0.0 \%)$ & \\
\hline Gastroplegia & $2(1.0 \%)$ & $1(1.4 \%)$ & \\
\hline Intestinal obstruction & $3(1.4 \%)$ & $0(0.0 \%)$ & \\
\hline Intraperitoneal bleeding & $4(1.9 \%)$ & $2(2.8 \%)$ & \\
\hline Systemic Complications & $3(1.5 \%)$ & $3(4.1 \%)$ & \\
\hline Pneumonia & $2(1.0 \%)$ & $3(4.1 \%)$ & \\
\hline Cardiovascular & $1(0.5 \%)$ & $0(0.0 \%)$ & \\
\hline
\end{tabular}




\begin{tabular}{|llll|}
\hline Table 4. Long-term Outcomes & & & \\
\hline Variable & Normal BMI & High BMI & P-value \\
\hline Follow-up Time (month; media) & $20(12.0-29.8)$ & $18(12.0-26.3)$ & 0.468 \\
\hline Relapse-free Survival & & & 0.812 \\
\hline No & $148(70.5 \%)$ & $49(68.1 \%)$ & \\
\hline Yes & $62(29.5 \%)$ & $23(31.9 \%)$ & \\
\hline Location of Recurrence & & & 0.419 \\
\hline Anastomotic recurrence & $18(8.6 \%)$ & $8(11.1 \%)$ & \\
\hline Distant nodal metastases & $19(9.0 \%)$ & $5(6.9 \%)$ & \\
\hline Liver metastases & $4(1.9 \%)$ & $2(2.8 \%)$ & \\
\hline Pelvic metastasis & $4(1.9 \%)$ & $0(0.0 \%)$ & \\
\hline Peritoneal metastasis & $9(4.3 \%)$ & $7(9.7 \%)$ & \\
\hline Other & $8(3.8 \%)$ & $1(1.4 \%)$ & \\
\hline Overall Survival & & & \\
\hline Dead & $24(11.4 \%)$ & $7(9.7 \%)$ & \\
\hline Alive & $186(88.6 \%)$ & $65(90.3 \%)$ & \\
\hline
\end{tabular}

\begin{tabular}{|c|c|c|c|c|}
\hline Risk Factor & $\beta$ & Hazard ratio & $95 \% \mathrm{Cl}$ & $P$ value \\
\hline Age ( $₫ 70$ vs. $\geq 70$ years) & 0.489 & 1.631 & $0.902-2.948$ & 0.106 \\
\hline Sex (male vs. female) & 0.291 & 0.747 & $0.466-1.199$ & 0.228 \\
\hline BMI (normal BMI vs. high BMI) & 0.185 & 1.203 & $0.745-1.944$ & 0.45 \\
\hline Operation time ( $\mathbb{1 5 0}$ vs. $\geq 150$ minutes) & 0.094 & 1.099 & $0.714-1.691$ & 0.668 \\
\hline Intraoperative blood loss ( $₫ 300$ vs. $\geq 300 \mathrm{ml}$ ) & 0.125 & 0.133 & $0.415-3.096$ & 0.807 \\
\hline Tumor invasion depth (T1/T2 vs. T3/T4) & 1.637 & 5.139 & $1.264-20.900$ & 0.022 \\
\hline Lymphatic metastasis (No vs. Yes) & 0.012 & 1.012 & $0.579-1.796$ & 0.967 \\
\hline Tumor size ( $₫ 5 \mathrm{vs} . \geq 5 \mathrm{~cm})$ & 0.585 & 1.794 & $1.109-2.904$ & 0.017 \\
\hline
\end{tabular}

Abbreviations: $\mathrm{Cl}$ (confidence interval). 


\begin{tabular}{|c|c|c|c|c|}
\hline Risk Factor & $\beta$ & Hazard ratio & $95 \% \mathrm{Cl}$ & $P$ value \\
\hline 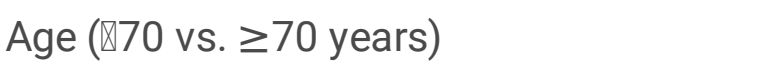 & 0.454 & 1.574 & $0.869-2.850$ & 0.134 \\
\hline Tumor invasion depth (T1/T2 vs. T3/T4) & 1.438 & 4.210 & $1.020-17.382$ & 0.047 \\
\hline Lymphatic metastasis (No vs. Yes) & 0.038 & 1.038 & $0.591-1.824$ & 0.896 \\
\hline Tumor size $(₫ 5 \mathrm{vs} . \geq 5 \mathrm{~cm})$ & 0.471 & 1.603 & $0.985-2.608$ & 0.058 \\
\hline
\end{tabular}

\section{Figures}

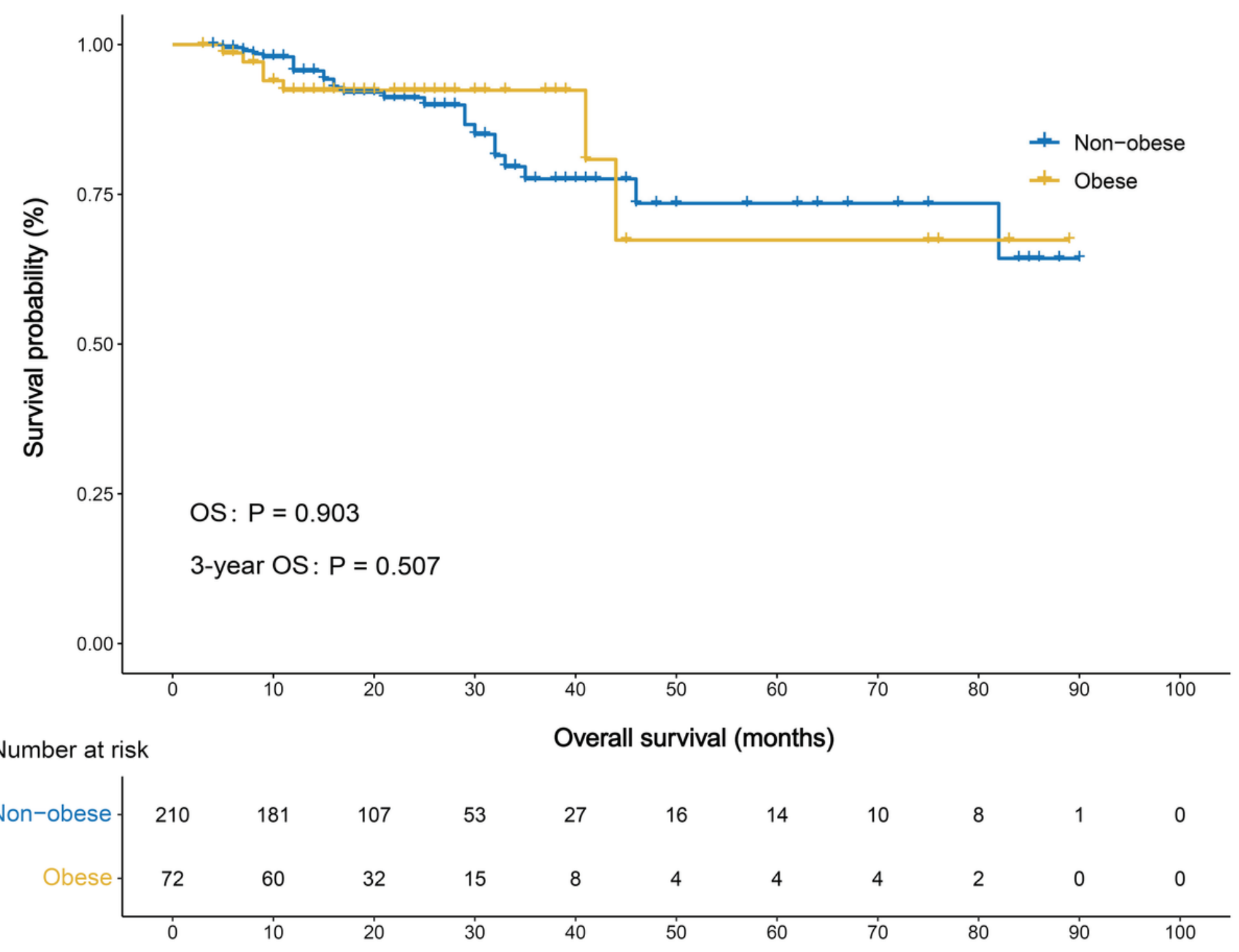

Figure 1

Overall survival of the normal BMI and high BMI groups. 


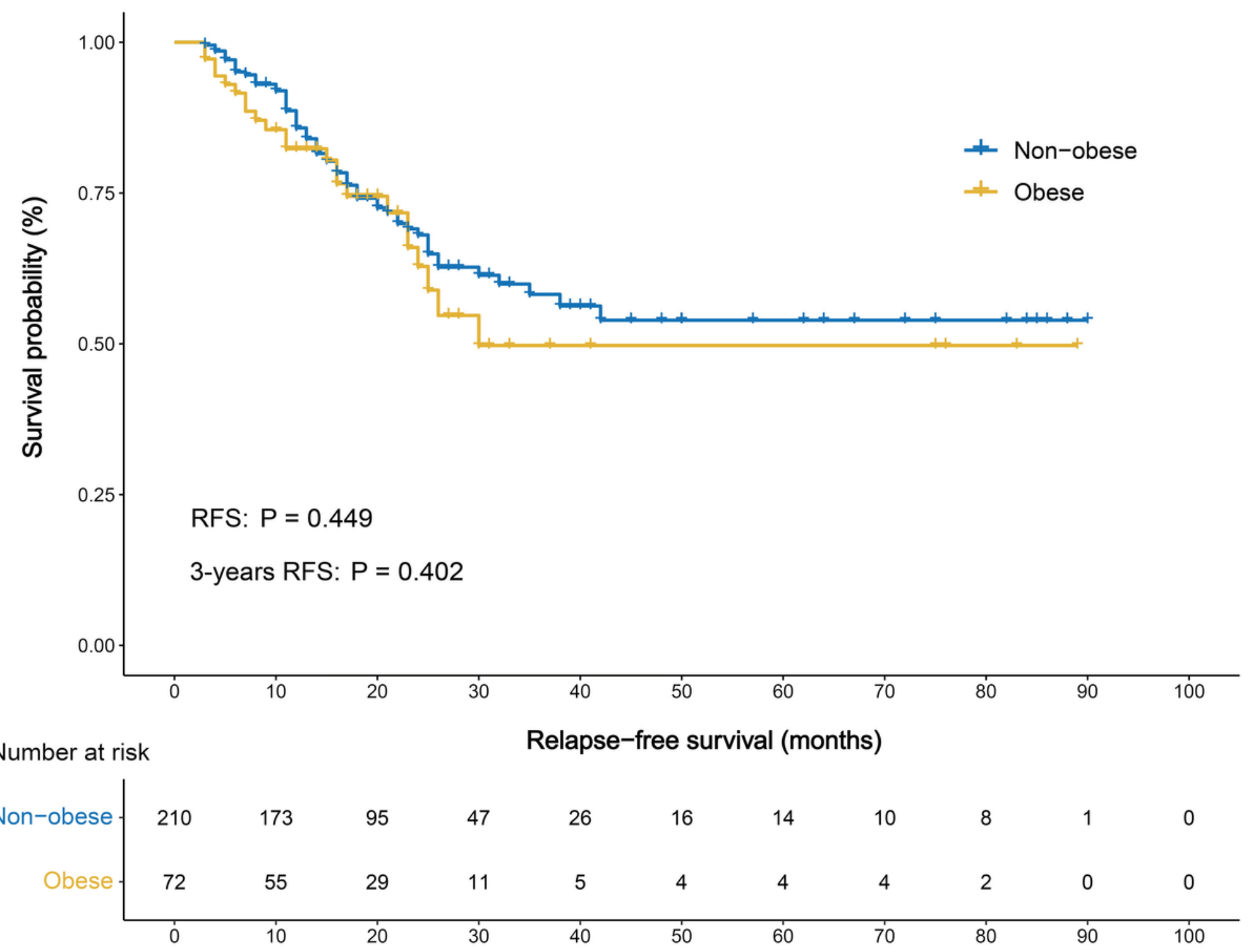

Figure 2

Relapse-free survival of the normal BMI and high BMI groups. 